\title{
New insights into the 1783 Laki eruption and plume evolution from high time resolution ice core isotope and cryptotephra analysis
}

\author{
WILLIAM HUTCHISON ${ }^{1}$, FLORIAN BROUILLET ${ }^{1}$ AND \\ ANDREA BURKE ${ }^{2}$ \\ ${ }^{1}$ School of Earth and Environmental Sciences, University of St \\ Andrews \\ ${ }^{2}$ University of St Andrews \\ Presenting Author: wh39@st-andrews.ac.uk
}

The ice core record preserves the finest time-resolved records of past volcanic events on Earth. Volcanologists have various tools for interrogating these records and two of the most powerful techniques are sulfur isotopes and analysis of cryptotephra. These analyses can provide detailed information about the source location, injection height and plume evolution. However, the vast majority of volcanic ice core horizons have only been sub-sampled and analysed at low time resolution, and this means isotopic signals are often averaged over many months, and that tephra records are rarely related to primary eruption and/or plume processes.

The 1783 Laki eruption is one of the largest eruptions of the last common era and is estimated to have injected 100-200 MT of sulfate into the atmoshpere as well as $15 \mathrm{~km}^{3}$ of tephra. Following/during the eruption e Europe experienced an exceptionally hot summer followed by a cold winter. In addition, following the eruption of the Laki, a "dry fog" appeared and remained for several months over Western Europe and even as far as North Africa. However, large uncertainties remain about the plume evolution in time and space, and the impact this had on north hemisphere climate.

To better understand the plume evolution of Laki we collected an exceptionally high time resolution record of the NGRIP ice core (which gives us $\sim 10$ samples/year).

We identified cryptotephra throughout this record, highly concentrate at certain time intervals, suggesting the record of several pulses in volcanic activity or plume deposition. These peaks come mainly at the same time and after sulfate peak, which is different to other cores (e.g Svalbar island). We will use SEM to analyse composition of tephra, estimates their abundance and variation in particle size throughout the sequence. Also, S isotopes analysis will be performed to understand the injection height and atmospheric chemical processing.

This high-resolution record will be use for test if ice core tephra peaks match with change in eruption style or change in plume direction and deposition. In Addition these tephra and $\mathrm{S}$ isotopes record will allow us to better understand the time-space evolution of the Laki plume. 